\title{
Mudança de Postura? A Conduta Cidadã no Uso de Sacola Plástica no Varejo
}

\author{
Viegas da Costa-Nascimento, Daniela; dos Santos de Sousa Teodósio, Armindo \\ Mudança de Postura? A Conduta Cidadã no Uso de Sacola Plástica no Varejo \\ Administração Pública e Gestão Social, vol. 11, núm. 3, 2019 \\ Universidade Federal de Viçosa, Brasil \\ Disponível em: http://www.redalyc.org/articulo.oa?id=351559268007
}

Esta obra está bajo una Licencia Creative Commons Atribución-NoComercial-SinDerivar 3.0 Internacional. 


\title{
Mudança de Postura? A Conduta Cidadã no Uso de Sacola Plástica no Varejo
}

\author{
Change of Posture? Citizen Conduct in the Use of Plastic Bag in Retail \\ ¿Cambio de postura? La Conducta Ciudadana en el uso de bolsas de plástico en el comercio
}

Daniela Viegas da Costa-Nascimento

Centro Universitário UNA, Brasil

Redalyc: http://www.redalyc.org/articulo.oa?

dvcnascimento@gmail.com

Armindo dos Santos de Sousa Teodósio

Pontifícia Universidade Católica de Minas Gerais, Brasil

armindo.teodosio@gmail.com

\section{Resumo:}

O artigo problematiza a postura de cidadãos, governo e empresas frente aos desafios da construção de ações e políticas capazes de renovar as práticas de consumo relacionadas à sustentabilidade, especificamente em relação à lei 9.529/08 de proibição da distribuição gratuita de sacolas plásticas pelo varejo, aprovada de forma pioneira em Belo Horizonte (MG). Além do estudo acerca da conduta da Prefeitura e de entidades envolvidas com a aprovação da lei, foi abordada também a aceitação da mudança por parte dos cidadãos. O estudo qualitativo envolveu entrevistas com consumidores acerca da lei, além da realização de entrevistas com representantes do legislativo e do executivo municipais e representantes de empresas sobre o projeto de lei. No caso da proibição das sacolas plásticas no município de Belo Horizonte, foram identificadas falhas que não permitiram o completo funcionamento do plano de ação da lei, apesar de se observar uma redução no uso de sacolas.

Palavras-chave: Sacolas Plásticas, Consumo, Sustentabilidade, Poder Local, Belo Horizonte.

\begin{abstract}
:
This paper discusses the posture of citizens, government and business related to the challenges of building actions and policies that renew consumer practices related to sustainability, specifically in relation to the law $9.529 / 08$, that prohibits the free distribution of plastic bags at retail, adopted for the first time in Belo Horizonte, in the state of Minas Gerais, Brazil. Besides the study about the conduct of government of Belo Horizonte city and organs involved with the approval of the law, the acceptance of the change by the citizens was also discussed. The qualitative study involved interviews with consumers about the law, in addition to conducting interviews with representatives of the municipal legislative, government and business about the law. In the case of the ban of plastic bags in the city of Belo Horizonte, failures were identified that did not allow the full implementation of the law's action plan, despite a reduction in the use of bags.
\end{abstract}

KEYWORDS: Plastic Bags, Consumption, Sustainability, Local Power, Belo Horizonte.

\section{Resumen:}

Este artículo problematiza la postura de ciudadanos, gobierno y empresas frente a los desafíos de la construcción de acciones y políticas capaces de renovar las prácticas de consumo relacionadas con la sostenibilidad, específicamente en relación a la ley 9.529/08 de prohibición de la distribución gratuita de bolsas plásticas por el comercio minorista, aprobada de forma pionera en Belo Horizonte, capital del estado de Minas Gerais, em Brasil. Además del estudio sobre la conducta del Ayuntamiento y de las entidades involucradas con la aprobación de la ley, se abordó también la aceptación del cambio por parte de los ciudadanos. El estudio cualitativo involucró entrevistas con consumidores acerca de la ley, además de la realización de entrevistas con representantes del legislativo y del ejecutivo municipales y representantes de empresas sobre el proyecto de ley. En el caso de la prohibición de las bolsas plásticas en el municipio de Belo Horizonte, se identificaron fallas que no permitieron el completo funcionamiento del plan de acción de la ley, a pesar de observar una reducción en el uso de bolsas.

Palabras clave: Bolsas Plásticas, Consumo, Sostenibilidad, Poder Local, Belo Horizonte. 


\section{INTRODUÇÃO}

O cidadão-consumidor tem sido incentivado a adotar mudanças de postura a partir do avanço com as preocupações ambientais no mundo no ato da compra, considerando a postura das empresas com relação ao meio ambiente (Lipovetsky, 2007; Okada \& Mais, 2010; Matos, 2013). Ações de ponto de venda, merchandising e marketing nas lojas e a disputa pela atenção do consumidor nos ambientes presenciais ou virtuais levam a um estímulo ao consumo, especialmente com o crescente acesso de todas as camadas sociais ao fenômeno das compras. $\mathrm{O}$ ato de consumir pode contribuir tanto para a satisfação de necessidades, melhorando a qualidade de vida e favorecendo o desenvolvimento local, quanto para a exploração de recursos e aumento da desigualdade social (Costa \& Teodósio, 2011).

No varejo, esses dilemas parecem estar mais evidentes, na medida em que o poder se centra na mão do consumidor. Criar uma cultura que alcance uma vida sustentável e com qualidade ainda parece utópico, já que qualquer consumo causa impacto na economia, relações sociais, meio ambiente e no próprio consumidor. Ao ter consciência do impacto das suas escolhas, o consumidor poderia maximizar as externalidades positivas e minimizar as negativas (Costa \& Teodósio, 2011).

O consumidor pode ser incentivado a fazer com que o seu ato de consumo seja um ato de cidadania, ao escolher em que mundo quer viver (Viegas, 2010). Cada cidadão tem a capacidade de optar por produtos e serviços que satisfaçam suas necessidades tentando não afetar o bem-estar da coletividade, atual ou futura (Lipovetsky, 1989; Canclini, 2006; Painter-Morland, Demuijnck \& Ornati, 2017).

Muitas vezes, porém, empresas almejam a visibilidade nas ações sustentáveis. O desafio é transformá-las em política organizacional, sensibilizando para a causa e conduzindo-as em direção à sustentabilidade. Porém, ações isoladas ou mesmo coletivas de empresas podem não conseguir promover a sustentabilidade nas bases necessárias frente a urgência dos problemas socioambientais que se apresentam, exigindo uma ação articulada entre governos, empresas, sociedade civil e cidadãos (Fisher, 2014).

Este artigo tem como objetivo analisar a aprovação e implementação da lei municipal 9.529/08, que instituiu a proibição da distribuição gratuita de sacolas plásticas pelo varejo, aprovada em Belo Horizonte, capital de Minas Gerais (MG), no dia 18 de abril de 2008, e que entrou em vigência em 2011, tanto na visão dos agentes políticos e entidades envolvidas, bem como a percepção de consumidores a respeito dos impactos de tal lei sobre o consumo no varejo supermercadista. Além da postura da Prefeitura de Belo Horizonte, foi abordada também a forma como a mudança foi comunicada à sociedade, tanto por parte do poder público local quanto pelos varejistas.

A lei no 9.529/08 “dispõe sobre a substituição do uso de saco plástico de lixo e de sacola plástica por saco de lixo ecológico e sacola ecológica, e dá outras providências” (Lei no 9.529/08). De iniciativa do vereador Arnaldo Godoy, foi publicada em 27 de fevereiro de 2008, com três anos para sua implementação. Nesse tempo, a proposta teve caráter facultativo para todos os estabelecimentos comerciais da cidade de Belo Horizonte, de forma que indústria e comércio de adaptassem às exigências: substituição de sacos e sacolas plásticas feitas de derivados do petróleo. Decorrido o prazo, a partir de 28 de fevereiro de 2011, passou a caráter obrigatório, estando o estabelecimento sujeito a sanções como notificação, multa, interdição e cassação dos alvarás de localização e funcionamento, em caso de infração.

Constitucionalmente, o poder público local é responsável o gerenciamento dos resíduos sólidos urbanos no Brasil (Instituto Brasileiro de Geografia e Estatística - IBGE, 2010). Em Belo Horizonte, a Superintendência de Limpeza Urbana (SLU) recolhe cerca de 2,8 mil toneladas de lixo por dia para uma população de aproximadamente 2,5 milhões de pessoas. Desse valor, são 500 toneladas de entulho e terra, 1.900 toneladas de resíduos domiciliares, 230 toneladas de resíduos de deposição clandestina, 50 toneladas de resíduos de varrição e 120 toneladas em coletas de limpezas diversas. Do total de resíduos, cerca de $1 \%$ é reciclado na capital (SLU, 2018). 
Invariavelmente, grande parte dessa quantidade de lixo diária é embalada em sacolas plásticas oriundas de estabelecimentos comerciais. Considerando que o tempo de decomposição do plástico é alto, pois "sua degradação é extremamente lenta e pode demorar mais de 100 anos até sua decomposição completa” (SLU, 2018), a Lei 9.529/08 apresenta um avanço na gestão do resíduo em Belo Horizonte, mas está distante de uma solução eficaz para o problema dos resíduos urbanos. Como metodologia, para analisar a percepção do consumidor acerca da lei, escolheu-se dois grandes supermercados de Belo Horizonte (MG), com perfis de público diferentes: o Martplus e o Supermercado $\mathrm{BH}$, para a realização de entrevistas estruturadas aos consumidores. O estudo qualitativo envolveu a realização de quatro entrevistas com representantes ou responsáveis pelo projeto de lei sobre as sacolas plásticas, escolhidos por seu elevado grau de envolvimento e tomada de decisões no processo de disseminação da lei: o vereador responsável pela criação da lei 9.529/08; o assessor da Agência de Comunicação do município; a assessoria de comunicação da Prefeitura e o diretor da Associação Mineira de Supermercadistas.

É possível perceber, a partir dos resultados de campo, que existe entre a maioria das pessoas que compuseram a amostra a consciência de que a sacola plástica é prejudicial ao meio ambiente e que qualquer questão que envolva as discussões voltadas aos problemas ambientais e bem-estar social devem ser apoiadas, com o engajamento da população. Porém, o caso de proibição das sacolas plásticas, apesar de ter sido convertido em ação devido à lei vigente, ainda não está devidamente absorvido na mudança de postura e compreensão mais aprofundada das pessoas em relação a esse problema.

\section{A EVOLUÇÃO DO MERCADO SUSTENTÁVEL}

As questões ambientais ganharam centralidade e repercussão pública nos últimos anos, frente à crise socioambiental, gerando um debate internacional que ressalta a necessidade de soluções urgentes (Jacobi, 1999; Naves, 2004; Sachs, 1986). Se o ritmo for mantido, na metade deste século se chegará a nove bilhões de habitantes e quatro bilhões de toneladas de resíduos urbanos por ano (Brasil, 2014). Dentre os elementos que constituem esse problema, estão o consumo crescente de bens e a rápida concentração da população em centros urbanos, com o consequente crescimento no volume de resíduos (Brasil, 2014).

Algumas condutas empresariais podem demonstrar avanço na consciência ecológica, como coleta seletiva de resíduos, uso eficiente da iluminação, economia e reaproveitamento de água, diminuição do lixo, conservação do solo, reciclagem de materiais, geração de emprego e renda pela comercialização dos recicláveis, criação de oportunidades de fortalecimento de cooperativas e arranjos produtivos locais ou parcerias (Boyer, 2015). É possível perceber certo crescimento do mercado sustentável no Brasil, como afirma Giacomini (2004, p. 27), com a abordagem das eco-empresas, "que trabalham com eco-negócios, são exemplos de atividades: brindes, embalagens, equipamentos de despoluição, móveis, consultoria de gestão ambiental, alimentação orgânica". Pode-se perceber diferentes frentes de ação disseminando-se entre as empresas, tais como a preocupação com a eco-eficiência, a busca de incentivos públicos para renovação de equipamentos e processos em termos menos agressivos ao meio ambiente, envolvimento da cadeia de suprimentos nas ações orientadas para a sustentabilidade, adoção de estratégias de cidadania corporativa, marketing responsável e diálogo com públicos envolvidos ou stakeholders (Silva \& Cândido, 2014). Porém, essas ações ainda são alvo de baixo controle social, colocando em suspeição sua própria eficácia. Mais importante é a crítica que demonstra como esse verdadeiro esverdeamento dos processos empresariais não é e não será capaz de promover a sustentabilidade por si só, dado o crescente aumento da produção e do consumo em termos mundiais (Abrovamay, 2012).

A mudança de hábito dos consumidores em relação a produtos ecológicos tem sido temática de estudos recentes (Chen \& Chain, 2010; Okada \& Mais, 2010; Matos, 2013). Essa transformação pode colaborar na implantação de políticas públicas em benefício do desenvolvimento de novos padrões de consumo. Outro fator que demonstra o desenvolvimento do mercado sustentável é o crescimento dos produtos 
ecológicos, diminuindo os impactos no ciclo de vida dos produtos, em um sistema de proteção, do produtor ao consumidor final, sem exploração de mão de obra (Brough, Wilkie, Ma, Isaan \& Gal, 2016). Esses tipos de iniciativas privilegiam fornecedores locais para valorização da economia, diminuindo o impacto do transporte até o mercado consumidor, o que significa a redução de poluição, tráfego e maior conservação dos produtos (Engelman, 2013). Além disso, os consumidores cada vez mais exigiriam transparência, na medida em que se colocam mais interessados nas práticas éticas das empresas (Semprebon et al, 2017).

Entretanto, não é qualquer ação ou empresa que efetivamente contribui para o avanço da sustentabilidade. "A maioria lança campanhas sem o devido conhecimento do tema ou respaldo na prática, o que pode afetar a percepção do público sobre a empresa, levando-a ao descrédito e ferindo sua reputação - ativo intangível vital para a perenidade do negócio" (Gife, 2011).

Apesar de incipiente, é possível perceber uma evolução no pensamento sustentável da sociedade e dos mercados (Antonetti \& Maklan, 2016). Esse desenvolvimento tem espelhado novas posturas no campo do consumo e do varejo, mesmo com desafios a serem superados. De acordo com Bauman (1999), a dinâmica social que orienta a ação dos indivíduos é pautada, em muitos momentos, pelo desejo e também por um verdadeiro "dever" de exercer o papel de consumidor no contexto das relações sociais contemporâneas, cada vez mais perpassadas pelo fenômeno do consumo como forma de sociabilidade. Canclini (2006) afirma que as identidades são configuradas através do consumo e dependem do que se possui ou possa possuir.

Entende-se o consumo como um processo sociocultural de apropriação e uso dos produtos e, portanto, em um sentido de compartilhamento dos sentidos dos bens (Canclini, 2006). Ele é uma forma de pertencimento, de apropriação coletiva, em relações de solidariedade e distinção com os demais indivíduos, que serve para satisfação biológica e simbólica e como uma forma de receber e enviar mensagens.

Os indivíduos viveriam na contemporaneidade uma sociedade marcada pelo hiperconsumo, um novo consumo com função identitária, na medida em que os indivíduos comprariam objetos para viver melhor, mais que somente para se exibir ou servir de símbolo de posição social (Lipovetsky, 1989). O hiperconsumo, ao mesmo tempo que poderia permitir o aparecimento de indivíduos mais conscientes, levaria esses sujeitos para uma vida de paradoxos, na busca pela felicidade.

O consumo significaria um canal de apropriação coletiva e constituição de relações com os demais indivíduos e teria a função de satisfazer e de promover formas de se comunicar, proporcionando vias de participação popular e desenvolvimento da cidadania (Canclini, 2006). Nesse sentido, propostas como a do consumo sustentável seriam mais alinhadas à transformação social necessária à promoção da sustentabilidade, pois priorizam as ações coletivas e as mudanças políticas, econômicas e institucionais, ultrapassando as questões tecnológicas e comportamentais, para garantir que as necessidades atuais e futuras da sociedade sejam atingidas (Portilho, 2005). O consumo sustentável não se limitaria a mudanças comportamentais de consumidores, mas priorizaria as ações, individuais ou coletivas, enquanto práticas políticas, o que implicaria na criação de sistemas mais sustentáveis de desenvolvimento (Gonçalves-Dias \& Teodósio, 2006).

Fontenelle (2009) aponta que as estratégias de produção e comunicação de mensagens voltadas para as práticas do consumo baseiam-se no conhecimento da realidade sociocultural dos grupos de indivíduos, causando uma pulverização dos canais de acesso ao consumidor, que atualmente ultrapassa os básicos anúncios comerciais e modificam formatos e linguagens para que a mensagem chegue adaptada a diferentes nichos de consumidores.

A sociedade de consumo privilegiaria a produção de signos e imagens em detrimento das mercadorias. A característica principal desse sistema seria a de apresentar um número extenso de bens, experiências e imagens para que o consumidor deseje e consuma mais. As estratégias publicitárias, juntamente com estereótipos criados pela mídia, adquirem grande relevância através da manipulação dos desejos do indivíduo. Esse crescimento pode ser vinculado à rapidez dos mercados ao explorar novas possibilidades e apresentar produtos, criando necessidades e desejos. $\mathrm{Na}$ visão tradicional de condução dos negócios, naturalizada na sociabilidade contemporânea, seria economicamente mais viável diminuir a vida útil das mercadorias, criando 
uma cadeia de sucessões, na qual os produtos vão se tornando obsoletos. (Costa et al, 2014). Esse princípio impulsiona o consumo, levando os indivíduos a uma relação efêmera com seus objetos consumo. (Slater, 2002).

É neste momento que, para Lipovetsky (2007), começa a surgir a sociedade do hiperconsumo: as satisfações sociais de diferenciação individual permanecem, porém são uma das motivações dentre as demais, formando um conjunto dominado pela busca da felicidade individual, em detrimento da coletiva. Lipovetsky (2007, p. 146-147) argumenta que existe uma esperança no hiperconsumo, não podendo ser assimilada totalmente "ao grau zero dos valores e dos comportamentos altruístas".

Segundo Dias (2007), pode-se perceber que já existem mudanças na forma de pensar da sociedade, os indivíduos estão mais conscientes de seus direitos e deveres e passam a enxergar que devem participar do processo de construção de uma sociedade mais justa. A sustentabilidade poderia ser viabilizada a partir da adoção, pelos sujeitos, de coerência nas suas atividades, tornando-a prática social (Hamman, Anquetin \& Monicolle, 2017; Shove, 2012;), que faça parte de sua rotina diária. Pesquisas recentes demonstram como as práticas são socialmente construídas, bem como o engajamento dos sujeitos junto às condutas coerentes com ações sustentáveis (Shove, 2012, 2012a; Chappells, Medd \& Shove, 2013).

De acordo com Shove (2012), as práticas cotidianas não nascem reduzidas a uma escolha individual e racional, pois estariam imbrincadas em infraestruturas de fornecimento, objetos e tecnologias, organização de espaços, construção de significados e normas sociais, influência das redes de relações, desenvolvimento de competências e hábitos incorporados (Shove, 2012a). Portanto, para que a sustentabilidade se dissemine, seria preciso articular as implicações políticas para constituir uma prática social ao invés de constituir atitudes individuais e isoladas. Uma simples instituição de regras não diminuiria a utilização de recursos, porque dependeria dos significados atribuídos pelos sujeitos às ações, como hábitos pertinentes às suas práticas diárias a partir de uma renegociação dos hábitos dos sujeitos (Shove, 2012).

Santos (2005) destaca que as organizações começam a adotar essa postura quando assumem a preocupação efetiva sobre os impactos socioambientais que sua produção e consumo geram. As empresas detêm um papel relevante para a mudança em direção à sustentabilidade, bem como as organizaçóes públicas e da sociedade civil, ao apoiarem (ou não) o estabelecimento de práticas responsáveis, constituindo estímulos para que mudanças de postura aconteçam no seio da sociedade (Silva \& Cândido, 2014; Silva \& Slongo, 2014).

\section{O DESAFIO DO VAREJO NA SUSTENTABILIDADE}

A ânsia pelo consumo de produtos, estimulada pela exaltação de tudo que é "novo", gera impactos na qualidade de vida e se torna, paradoxalmente, agente agravante da condição humana e planetária. De acordo com Lipovetsky, "precisamos claramente de menos consumo, entendido como imaginário proliferativo da satisfação, como desperdício da energia e como excrescência sem regra das condutas individuais". (Lipovetsky, 2007, p. 19). De acordo com o autor, é preciso regulação e moderação, além de depender menos dos bens mercantis na vida cotidiana. Por outro lado, Lipovetsky (2007, p. 19) defende que "precisamos também, sob certos aspectos, de mais consumo: isso, para fazer recuar a pobreza, mas também para ajudar os idosos e cuidar sempre melhor das populações". (Lipovetsky, 2007, p. 19)

O setor varejista tem se organizado, tradicionalmente, a partir da visão de quem tem como principal missão a promoção ativa do consumo. Para garantir o crescimento do seu negócio, os varejistas procuram convencer as pessoas a comprarem mais produtos, com mais frequência. Para se encaixar nesse novo momento do mercado, no qual as preocupações quanto à sustentabilidade têm ganhado força, o setor varejista precisaria rever a quase totalidade de suas estratégias de condução dos negócios. O consumo sustentável faz parte de um debate ao qual as empresas de varejo precisam se engajar, caso queiram tomar decisões para sustentabilidade da sociedade e de seu negócio (Knight, 2004). 
No processo de sensibilização para o consumo sustentável, os varejistas podem assumir, claramente, um papel importante e aproveitar uma de suas principais características: contato direto com o consumidor final. O varejo é um dos setores mais relevantes quando está em tela a conexão mais direta com o cidadão no seu cotidiano. De acordo com Belinky (2006), o papel do segmento varejista é fundamental no exercício da cidadania. "Nenhum outro setor tem uma relação tão próxima e interativa com o nosso novo ator social: o consumidor cidadão. A partir desta condição privilegiada de comunicação, o setor varejo pode fazer muito pela boa informação". (Belinky, 2006, p.43). Dessa maneira, "o varejo assume uma nova dimensão, neste novo mundo, onde o mercado é tão importante. É a dimensão não de um local de compras, mas a de um fórum permanente para exercício da cidadania ativa pela via do consumo". (Belinky, 2006, p.44).

Além disso, a intermediação entre fornecedor-consumidor beneficiaria o varejo e permitiria operação sobre as duas pontas da cadeia de produtos e serviços. Dessa forma, as empresas de varejo podem aplicar os princípios de sustentabilidade na gestão do seu negócio e influenciar seus fornecedores para que façam o mesmo, acarretando em mudanças na cadeia produtiva. Do outro lado, as empresas de varejo podem estimular o consumidor a optar por uma postura na qual as preocupaçóes com a sustentabilidade sejam mais presentes, ofertando produtos que atendam critérios socioambientais em seu processo de produção e disponibilizando informações sobre a importância das atitudes individuais para o processo de construção da sustentabilidade. Os objetivos e o sentido da produção precisariam se voltar para as necessidades básicas e a ampliação das liberdades humanas, respeitando as possibilidades da natureza (Abramovay, 2012). Parente (2004, p. 12) afirma que "o desenvolvimento da responsabilidade social no varejo ajuda também a estender as práticas socialmente responsáveis à cadeia produtiva”. De acordo com Macedo (2007), o varejo possui grandes oportunidades de agir de maneira mais sustentável, contribuindo para o desenvolvimento das comunidades, como apoiar movimentos ambientais, inserir novas linhas de produtos sustentáveis no mercado, "participar de iniciativas que promovam o desenvolvimento da região em que a loja está inserida e, por consequência, a melhoria da qualidade de vida da população, que se desdobra em milhões de consumidores, que por sua vez, sustentam a atividade varejista”. (Macedo, 2007, p.28).

Uma das práticas mais comuns das empresas varejistas é a distribuição, normalmente gratuita, de embalagens descartáveis - notadamente as sacolas plásticas -, para que o consumidor possa transportar as mercadorias adquiridas. As "sacolinhas", como ficaram conhecidas no cotidiano dos brasileiros, ganharam força nas décadas de 1980 e 1990, tendo surgido nos Estados Unidos em 1957 (Cherrier, 2007), em substituição às sacolas de papel. A substituição dessas embalagens por embalagens retornáveis e mais duráveis confirma a capacidade do setor varejista em estimular o consumidor a adotar posturas mais favoráveis à construção da sustentabilidade. Ações como essa poderiam ser incorporadas por diversos segmentos do varejo, evidenciando o potencial de disseminação de uma cultura de consumo mais adequada aos princípios da sustentabilidade, assunto que será discutido na análise das pesquisas de campo. Ainda assim, a abolição das "sacolinhas" é alvo de controvérsias envolvendo setores produtores de plásticos e intensas disputas entre movimentos ambientais, governos e diferentes segmentos empresariais sobre seu efetivo significado para a sustentabilidade.

\section{PROCEDIMENTOS METODOLÓGICOS}

Este estudo de natureza descritiva, analisa, a aprovação e implementação da lei municipal 9.529/08, tanto na visão dos agentes políticos e das entidades envolvidas, bem como a percepção de consumidores a respeito dos impactos de tal lei sobre o consumo no varejo supermercadista. Além da postura da Prefeitura de Belo Horizonte, foi abordada também a forma como a mudança foi comunicada à sociedade, tanto por parte do poder público local quanto pelos varejistas. Para entender esta abordagem de informação aos cidadãos, sob o ponto de vista documental, foi analisada a campanha de comunicação produzida para divulgação da lei das sacolas plásticas e seu clipping, além do estudo da própria lei desde sua entrada em vigor, em 2011. 
O clipping foi cedido temporariamente pela empresa de comunicação pesquisada e contemplou veículos de comunicação regionais como o Jornal Estado de Minas, O Tempo, Hoje em Dia e Diário do Comércio, no período de lançamento da campanha de comunicação. Intitulada "Sacolas Plásticas Nunca Mais", a campanha foi assinada por um conjunto de instituições ligadas ao consumidor e órgãos do governo: Prefeitura Municipal de Belo Horizonte (PBH), Sindicato e Associação Mineira da Indústria de Panificação (Amipão), Programa de Defesa do Consumidor (Procon), Movimento das Donas da Casa e Consumidores de Minas (MDC-MG), Mercado Central, Federação do Comércio de Bens, Serviços e Turismo do estado de Minas Gerais (Fecomércio), Câmara de Dirigentes Lojistas de Belo Horizonte (CDL-BH), Sindicato do Comércio Varejista de Gêneros Alimentícios de Belo Horizonte (Sincovaga), Associação Mineira de Supermercados (AMIS) e Associação Comercial e Empresarial de Minas (ACMinas). Começou a ser divulgada dia 28 de fevereiro de 2011 e terminou após 15 dias. Foi composta por folhetos e cartazes distribuídos a pontos de venda da capital em que havia distribuição de sacolas plásticas aos consumidores. Além disso, a campanha envolveu anúncios em televisão e backbus, informativos em rádios e nos sítios eletrônicos dos órgãos parceiros da campanha.

Em relação aos estudos de campo com foco qualitativo, foram feitas quatro entrevistas semi-estruturadas em profundidade e presenciais: com o vereador autor da lei, com o assessor de comunicação da Prefeitura de Belo Horizonte (PBH), com o assessor chefe de comunicação da agência de publicidade, que atende a PBH, e com o diretor de comunicação da AMIS, todas com média de duração de uma hora. As entrevistas foram realizadas no mês de maio de 2011 e transcritas na íntegra.

Foram feitas entrevistas de campo utilizando como instrumento um questionário estruturado, conduzido presencialmente pelos pesquisadores em supermercados de Belo Horizonte, abordando a opinião dos consumidores em relação à nova lei 9.529/08 e como reagiam a esse novo hábito. O mapeamento foi realizado em supermercados com perfis diferenciados: Martplus, na zona sul da cidade, e o Supermercado BH, na zona norte. Foram realizadas 100 entrevistas estruturadas nos supermercados, sendo 50 em cada perfil de supermercado. A amostra foi determinada por conveniência e por cota, uma vez que os supermercados escolhidos possuem perfis diferenciados entre si, sendo um deles mais sofisticado e outro, popular. A faixa etária dos respondentes foi de 20 até os 75 anos para ambos os supermercados. As entrevistas foram realizadas no mês de maio de 2011. Como o foco da pesquisa é qualitativo, não se pretendeu explorar estatisticamente a amostra. A definição da quantidade de entrevistas ocorreu por critério de saturação dos dados, na medida em que os pesquisadores identificaram excesso de repetição das informações colhidas em campo.

Quadro 1 - Técnica de pesquisa, público entrevistado e período de pesquisa

\begin{tabular}{|c|c|c|}
\hline Técnica & Público & Periodo \\
\hline \multirow{4}{*}{$\begin{array}{l}\text { Entrevista em } \\
\text { profundidade presencial }\end{array}$} & Vereador autor da lei & Maio de 2011 \\
\hline & Assessor de comunicação da PBH & Maio de 2011 \\
\hline & Assessor chefe da agência de comunicação da PBH & Maio de 2011 \\
\hline & Diretor de comunicação da AMIS & Maio de 2011 \\
\hline \multirow[t]{2}{*}{ Pesquisa documental } & $\begin{array}{l}\text { Campanha de comunicação para divulgação da lei das } \\
\text { sacolas plásticas }\end{array}$ & \multirow[t]{2}{*}{$\begin{array}{l}\text { Maio de } 2011 \text { a } \\
\text { novembro de } 2016\end{array}$} \\
\hline & $\begin{array}{l}\text { Lei } 9.529 / 08 \text { e acompanhamento das suas substituições } \\
\text { Clipping de jornais, revistas e sites sobre a lei }\end{array}$ & \\
\hline \multirow{2}{*}{$\begin{array}{l}\text { Entrevista pessoal } \\
\text { presencial - Questionário }\end{array}$} & 50 clientes do Supermercado Martplus (Zona Sul de BH) & \multirow[t]{2}{*}{ Maio de 2011} \\
\hline & 50 clientes do Supermercado $\mathrm{BH}$ (Zona Norte de $\mathrm{BH}$ ) & \\
\hline
\end{tabular}

Fonte: Os autores.

Foi realizada análise de conteúdo descritiva dos dados (Bardin, 2011), delimitada por característica das informações coletadas: primeiramente foi feita a análise das entrevistas em profundidade e, posteriormente, a 
análise dos resultados dos questionários aplicados nos supermercados, realizando-se triangulação desses dados colhidos com as entrevistas em profundidade, como forma de comprovação e checagem das informações.

\section{DESAFIOS DA PROIBIÇÃO DA DISTRIBUIÇÃO DE SACOLAS PLÁSTICAS NO VAREJO DE BELO HORIZONTE}

A Superintendência de Limpeza Urbana (SLU) é o órgão da Prefeitura Municipal de Belo Horizonte (PBH) responsável pela administração de resíduos sólidos na cidade. Chega a atender $95 \%$ da população da capital mineira com seu modelo de gestão de resíduos. Através de atuação política, possui ações voltadas para a preocupação ambiental, social e econômica, coletas domiciliar e coletiva e execução dos serviços de limpeza urbana para implementar e manter o Sistema de Limpeza Urbana e as metas dispostas no Plano Diretor de Resíduos Sólidos (Portal da Prefeitura de Belo Horizonte, 2011).

A lei 9.529/08, que extinguiu o uso de sacos de lixo e sacolas plásticas em Belo Horizonte, vigente desde 18 de abril de 2011, vem causando polêmicas. Inicialmente, é possível encontrar entre os consumidores, acostumados com a entrega "gratuita" das sacolas plásticas para embalar as mercadorias - na verdade, o valor das sacolas sempre foi embutido no preço das mercadorias -, uma divergência entre aqueles que afirmam que, por um lado, a mudança é benéfica para o meio ambiente, e aqueles, por outro, que se perguntam como farão para levar as compras para casa e, principalmente, reclamam que não poderão mais utilizar as sacolinhas para embalar outros materiais, incluindo o lixo doméstico.

Foram entrevistados alguns representantes municipais para entender as convergências e confrontos de opiniões sobre os desafios da sustentabilidade. Primeiramente, analisou-se a campanha de divulgação "Sacolas Plásticas Nunca Mais", que começou a ser divulgada dia 28 de fevereiro de 2011 e terminou após 15 dias. A mensagem principal era "Sacolas plásticas nunca mais. O futuro está em nossas mãos. Belo Horizonte, primeira capital sem sacolas plásticas convencionais. Faça parte desta campanha. $\mathrm{O}$ planeta agradece" (Associação Mineira de Supermercadistas, 2011). Em seguida, o folheto informa a data a partir da qual as sacolinhas não seriam mais distribuídas e apresenta alternativas ao consumidor: "traga suas sacolas, seu carrinho de feira, cestas ou outras embalagens retornáveis. Ou então, compre sacolas ecológicas compostáveis nos postos de venda”. (Associação Mineira de Supermercadistas, 2011).

Nos folhetos distribuídos nos estabelecimentos comerciais da capital, na parte superior, encontra-se a marca da campanha, uma sacola em formato de placa de proibição, e na parte inferior, sugestóes de utensílios alternativos para levar as compras, como ecobag, sacola de palha, carrinho, caixote de plástico e caixa de papelão. No verso do folheto, há explicações sobre o porquê de não usar sacolas plásticas convencionais, incentivos para usar sacolas retornáveis para as compras e a venda de sacolas biodegradáveis por R \$ 0,19. Essa informação da venda de sacolas plásticas, de acordo com o estudo realizado nos Supermercados BH e MartPlus, não agradaram os consumidores, que reclamaram que, mais uma vez, o custo da transformação social e ambiental seria remetido ao consumidor.

Para os entrevistados, a campanha foi veiculada "muito em cima da hora", sendo que o slogan "sacolas plásticas nunca mais" pareceu assustar os cidadãos, pois muitos consumidores em um primeiro momento pensaram que não haveria mais nenhum tipo de sacola. De modo geral, a campanha foi pouco informativa e poderia ter acontecido de forma mais criativa, trabalhando o apoio dos supermercados, por exemplo, com ações de "dia ecológico", envolvendo atrações culturais relacionadas à lei. A campanha não foi tão efetiva, pois, apesar da anuência de parte da sociedade, os consumidores foram mal informados e o processo de educação, que poderia ter ocorrido antes de a lei entrar em vigor, não foi feito.

O fato de muitos consumidores passarem a levar suas sacolas ao comércio pode indicar que não ocorreu rejeição à lei. A campanha, que consistiu em cartazes, banners e inserções na TV, poderia ter ido além, como ações nos estabelecimentos, palestras e workshops explicando aos consumidores com antecedência os benefícios da lei. Quanto à venda de sacolinhas, a campanha poderia enfatizar o porquê do custo, 
ressaltando que seu uso agride o ambiente. Uma campanha completa começaria com o envolvimento prévio dos consumidores, planejamento da implantação (possivelmente gradativa entre os setores do varejo) e se daria na antecipação da notícia, criatividade nas ações e explicação detalhada de como foram elaboradas as estratégias de implantação.

\section{Análise das Entrevistas em Profundidade}

Em visita à Câmara Municipal de Belo Horizonte, foi realizada uma entrevista com o responsável pela lei 9.529/08, um vereador do município que atualmente cumpre seu sexto mandato, cujas opiniões foram relevantes para entender como foi o seu processo de criação da proposta. De acordo com o entrevistado, o processo de desenvolvimento da lei foi participativo, envolveu discussões em audiências públicas que levaram à aprovação da lei quando colocada em votação.

Começamos pelas audiências públicas, trouxemos todos os segmentos envolvidos, arquitetos, cientistas, cidadãos comuns, representantes de sindicatos e, logo depois, a câmara aprovou o projeto em primeiro e segundo turno. Em segunda instância, passou pela sanção do prefeito em fevereiro de 2008, com o prazo para início de três anos para a campanha educativa e entrou em vigor em abril. (Entrevista com vereador, 2011)

Desde o dia 18 de abril de 2011, a lei vem sendo aplicada em todos os estabelecimentos comerciais de Belo Horizonte. No início a maioria dos consumidores resistiram mas, de acordo com o vereador, "a educação é à base de tudo e as pessoas vão se acostumando, exemplo disso é o uso de cinto de segurança" (Entrevista com vereador, 2011). O vereador acredita que através da educação, os clientes dos supermercados vão se adaptar à lei. Para haver transformação de posturas de fato, seria necessário reeducar em todas as esferas da vida contemporânea, inclusive e sobretudo no contexto do consumo.

Essa mudança significaria uma efetiva mudança de concepção de políticas públicas para a sustentabilidade, não se restringindo a mudanças pontuais como a proibição das sacolas plásticas, que, apesar de representar um começo de mudança, ainda não indica uma nova concepção, mais arrojada e efetiva em direção à sustentabilidade, nas políticas públicas do município. O vereador defende a lei afirmando que a intenção é evitar o uso de plástico em Belo Horizonte, a fim de "melhorar o tratamento dos aterros sanitários, e despertar a consciência de nossas crianças e jovens para que os mesmos provoquem em nós, adultos, uma mudança de comportamento e estilo de vida em médio prazo" (Entrevista com vereador, 2011). Após o cumprimento da lei, o esperado é que o aterro sanitário seja mais bem tratado e que o lixo orgânico possa ser melhor utilizado, inclusive visando a utilização do aterro para gerar energia, reciclagem de outros produtos, evitar enchentes, entre outros (Entrevista com vereador, 2011).

Além da resistência inicial dos consumidores em relação à lei, houve manifestação da indústria do plástico, rejeitando a decisão. De acordo com o vereador, representantes da indústria chegaram a se reunir em Belo Horizonte: "essa rejeição deu-se desde o governo Serra, [quando a] Assembleia do Estado de São Paulo aprovou a lei e o Serra vetou, porque a indústria do plástico fez o 'lobby', pressionou os interesses próprios e econômicos no governo e ele vetou" (Entrevista com vereador, 2011). Segundo o entrevistado, com o apoio de Márcio Lacerda (então prefeito de Belo Horizonte), a lei entrou em vigor: "a indústria do plástico terá que se adaptar, direcionar os investimentos para outros produtos e formatos, utilizar essa atividade econômica de forma criativa, que faça o bem e não agrida o meio ambiente, buscar novas alternativas" (Entrevista com vereador, 2011).

As manifestações não impediram que a lei entrasse em vigor. Atualmente já existem fabricantes que fazem sacolas plásticas biodegradáveis e retornáveis. Uma vez que a extinção de sacolas plásticas já acontece em vários países como Irlanda, Alemanha e Japão, no Brasil a lei tomou proporção nacional, sendo aprovadas leis semelhantes também na cidade de São Paulo (SP) e discutidas normas legais parecidas em várias capitais, tais como Aracaju (SE), Brasília (DF), Campo Grande (MS), Cuiabá (MT), Curitiba (PR), Florianópolis 
(SC), Fortaleza (CE), Goiânia (GO), João Pessoa (PB), Macapá (AP), Maceió (AL), Manaus (AM), Natal (RN), Palmas (TO), Porto Alegre (RS), Recife (PE), Rio de Janeiro (RJ), São Luís (MA), Teresina (PI) e Vitória (ES) (Reportagem retirada do sítio eletrônico G1,2011), o que indica que a mudança poderia assumir parâmetros estruturais no contexto brasileiro.

Outra questão debatida e que gerava controvérsias era relacionada ao possível desemprego provocado pela nova lei, em relação às fábricas de sacolas plásticas convencionais. O criador da lei 9.529/08 ressalta: "Estou ciente de que muitos irão ser demitidos, mas ao longo da história toda mudança gera incômodo e novas alternativas e soluções devem ser criadas" (Entrevista com vereador, 2011). O fato é que, de acordo com o entrevistado, muitos teriam que adaptar seus produtos e serviços à nova lei, se quisessem manter-se no mesmo segmento ou então, mudar de setor e/ou profissão.

O vereador critica a postura da Prefeitura em relação à divulgação da lei, pois, segundo, ele a conscientização deveria ter maior periodicidade e ser mais aprofundada. Como a lei foi aprovada em 2008, os atores ligados ao comércio e à Prefeitura estavam sabendo dos prazos e nada foi feito para que a população fosse envolvida, informada e mobilizada previamente, segundo o entrevistado: "Prevíamos uma campanha educativa de três anos para informar e preparar a população, o comércio do [conteúdo de] que se tratava a lei e a prefeitura não executou, iniciou suas ações e uma campanha massiva apenas nos últimos meses" (Entrevista com vereador, 2011). Isso foi prejudicial para o projeto, mas mesmo assim, "durante os três anos tivemos algumas inserções, muitas vezes espontaneamente pelos jornais, TV's educativas - universitárias e culturais - e emissoras de rádio, a CDL [Câmara de Dirigentes Lojistas], a Associação Comercial de Minas, todas estavam informadas" (Entrevista com vereador, 2011).

O resultado da falta de divulgação por parte da Prefeitura foi o desconhecimento da população. O que contribuiu para a campanha foi a união de outros órgãos, citados a seguir nesta análise. Como comprovado nos levantamentos aplicados mediante entrevistas com consumidores, a responsabilidade pela informação e educação da população sobre a lei não foi da campanha de divulgação, mas da repercussão da mídia e das discussões populares em torno da mudança. Reconhece-se que uma ação não exclui a outra, mas a propaganda poderia ter tido uma posição mais proativa, já que seu poder é conhecido na sociedade, desde que realizada com planejamento, tempo, criatividade e eficácia. Conforme fala Dias (2007, p. 31), "a consciência ecológica [...] aumenta através da recordação e da informação que se faz chegar ao consumidor sobre os produtos e marcas ecológicas, especialmente mediante a tangibilização dos benefícios, os conhecimentos e as crenças ecológicas que o consumidor mantém”.

Sem informação necessária, torna-se mais difícil a mudança de compreensão sobre a realidade ambiental das sacolas plásticas por parte da sociedade. As ações de fiscalização e difusão da aplicação por parte do poder público municipal não aconteceram com a intensidade e frequência necessárias. No que tange à ampliação da lei para todo o estado de Minas Gerais, como afirmou o vereador, essa preocupação deve tomar proporção equivalente.

Em visita ao departamento de comunicação da $\mathrm{PBH}$, foram informados diversos nomes para responder como foi o processo de implantação da lei 9.529/08, até chegar ao real responsável em atender as demandas sobre assuntos ligados ao meio ambiente e responsabilidade social. Quando foi possível conversar com uma pessoa diretamente ligada ao projeto, foi informado que:

Quem cuida da parte de enviar notícias sobre a questão da lei para a sociedade são em especial duas empresas, a agência de comunicação empresarial que está voltada para fornecer serviços para veículos de comunicação, e a AMIS, responsável em [sic] divulgar as campanhas para o grande público, apoiadas pelos órgãos como FECOMÉRCIO, CDL-BH, Sincovaga, Amipão, Procon e Mercado Central. (Entrevista com a assessora de comunicação da PBH, 2011)

Em um dos órgãos que mais deveria dar apoio à conscientização em massa agiu de maneira incompleta, foi possível constatar uma postura que transferia a responsabilidade da divulgação a outros órgãos. $\mathrm{Na}$ tentativa de colher material para pesquisa em dados secundários, como clipping e material da campanha, os pesquisadores não obtiveram sucesso para o atendimento da demanda. Não foi possível identificar se houve 
alguma restrição política no não repasse de informações, mas como os dados são de caráter público, deduzse que a falta de informações se refere a uma ausência de organização do setor de comunicação e a uma transferência de responsabilidade da questão para a agência e outras entidades envolvidas. No sítio eletrônico da $\mathrm{PBH}$, é possível encontrar apenas um artigo, publicado no dia em que a lei entrou em vigor, com opiniões dos cidadãos, todas positivas, além de sugestões do Secretário Municipal de Serviços Urbanos, para utilizarem sacola e caixas de papelão para as compras.

Com 20 anos de atuação no mercado, a agência de comunicação que atende a PBH é uma empresa voltada para a divulgação serviços de comunicação empresarial em todo o país. Em Belo Horizonte, um dos seus trabalhos é comercializar notícias aos canais de comunicação. Em entrevista com um dos assessores da agência, enxerga-se de maneira mais detalhada como foi o planejamento da campanha de divulgação da lei 9.529/08. De acordo com o assessor, com a criação da campanha:

Houve por parte da imprensa uma rejeição considerável, pois eles [membros da imprensa] ficaram inseguros e pensando qual seria outra solução, já [em relação à percepção dos] os consumidores, no final da campanha, 70\% se adaptaram de forma positiva a nova lei (Entrevista com representante da Agência de Comunicação, 2011).

É possível deduzir que houve grande adesão da população simplesmente pela obrigação, ou seja, ao se chegar no caixa do supermercado e ter que pagar pela sacolinha plástica, automaticamente o consumidor se adaptou à mudança, mesmo com alguma rejeição. Essa mudança, que poderia ter sido conduzida por meio de campanhas educativas, não ocorreu. Ela foi feita por imposição do fator custo e do fator lei, o que não agradou a maioria dos consumidores. A campanha foi mal divulgada no sentido de ter sido veiculada inicialmente em apenas dois jornais de Belo Horizonte. Para o entrevistado, é possível perceber que o supermercado, na verdade, é apenas um intermediário, não interferindo muito no processo de decisão dobre a mudança da lei.

O supermercado não tem interesse em vender as sacolas e que quem lucra efetivamente com estas vendas são os fabricantes de plástico, e que antes de começar a campanha, aconteceram uma série de consultas com o setor jurídico. Em um mês sem o uso das sacolas em BH [Belo Horizonte], a agência realizou um balanço dos impactos do lixo na capital e concluiu que foram 60 toneladas aproximadamente a menos de lixo do dia 18-04 a 18-05-2011" (Entrevista com representante da Agência de Comunicação, 2011).

Nessa fala constata-se a falta de envolvimento dos supermercados na campanha da mudança das sacolas. Os folders simplesmente ficaram disponíveis em um canto dos caixas, esperando-se que o consumidor os retirasse sem maiores estímulos. Poucos cartazes e banners foram afixados.

Alguns supermercados em Belo Horizonte criaram ações mais impactantes, como foi o caso do Verdemar, que vinha desenvolvendo há meses ações de conscientização, como a venda a preço de custo de sacolas retornáveis desenhadas pelo estilista Ronaldo Fraga, ou o hipermercado Extra, que desenvolveu a campanha “Terça sem sacola Extra”, a partir do segundo semestre de 2010, quando era sugerido o uso caixas de papeláo e/ ou de sacolas retornáveis para diminuir o número das tradicionais sacolas. A iniciativa foi inspirada em ações do Grupo Pão de Açúcar que, desde 2008, faz campanhas para conscientizar os clientes sobre a necessidade de diminuição do uso de sacolas plásticas. Outra observação na fala do assessor foi a diminuição do lixo em 60 toneladas em Belo Horizonte em um mês de campanha, o que indica que a lei é significativa em termos quantitativos e que pode gerar desdobramentos frente a outros problemas ambientais.

Em visita à AMIS, foi entrevistado o diretor do departamento de comunicação, segundo o qual "a campanha iniciou-se com o surgimento da lei, da pressão da opinião pública e pela indústria de plástico”. Para ele, diante de tantas manifestações e polêmicas em torno da nova lei, foi fundamental que se projetasse uma campanha para divulgar novas formas de consumo, sem a sacola plástica convencional.

Sobre a criação da lei em si, o entrevistado critica a atuação do fundador da lei: "A lei até então criada pelo vereador não passa de mera cópia de uma série de leis que outros vereadores já tinham sugerido e que era incentivada pela indústria do plástico". Perguntado sobre a questão das sacolas biodegradáveis e oxibiodegradáveis, ele se limitou a dizer: "As oxibiodegradáveis são extremamente poluentes ao meio 
ambiente". De fato, elas poluem pela elevada quantidade de componentes químicos empregada em sua rápida decomposição, mas com o surgimento das sacolas biodegradáveis, seus componentes amenizam os impactos, pois são compostas por elementos que, quando degradados, não poluem como o amido de milho, a batata entre outros. Muitos são os projetos de lei que incentivam o não uso de sacolas plásticas, porém, em pouquíssimos estados a lei saiu do papel, que estão aguardando as leis serem aprovadas nos parlamentos e/ ou serem aplicadas.

O diretor afirma que seriam necessários mais recursos para uma correta divulgação. De acordo com o entrevistado, o grau de instrução dos indivíduos também interfere na aceitação da nova lei.

Foi feito um levantamento nas classes A e B e a aceitação da lei das sacolas foi maior, já na classe C, 35\% aproximadamente adotaram a lei e nas classes D e E, o percentual foi extremamente baixo, por volta de $10 \%$ (Entrevista com diretor de comunicação da AMIS, 2011).

De acordo com o diretor, na primeira semana da nova lei, nos supermercados "a cada dez consumidores, seis estavam chegando sem nenhum tipo de sacola retornável e compravam as sacolas plásticas novas, e só quatro traziam ecobags". No primeiro mês, o número começou a melhorar, pois a cada dez consumidores, "sete já estavam se adaptando, mas ainda um número pequeno se adaptava com total satisfação. Atualmente, em média três consumidores ainda não levam nada para as compras e dois dificilmente irão levar" (Entrevista com diretor de comunicação da AMIS, 2011).

A compra de sacolas também acabou influenciando na ampliação da insatisfação dos clientes. Nesse sentido, a falta de uma campanha mais intensa e duradoura para educá-los contribuiu de forma significativa para que esse quadro se agravasse. A campanha de massa da AMIS, juntamente com outros parceiros envolvidos, se deu através de pontos de venda (PDVs), TV e mídia espontânea, 50 dias antes do dia 18 e continuou durante 15 dias após a lei. De acordo com o entrevistado, em média $85 \%$ da população já está aderindo à nova lei (Entrevista com diretor de comunicação da AMIS, 2011).

Seria necessário um maior envolvimento com os cidadãos, porém, a campanha demorou a ser divulgada, de forma que pudessem fixar as informações. O papel de cidadão poderia ser melhor exercido, as pessoas poderiam participar e contribuir para a sustentabilidade. Faltou comprometimento dos responsáveis e impactados pela implementação da lei, clareza e antecipação das informações. Torna-se cada vez mais necessário promover o "relacionamento humano, até como forma de garantir o exercício da cidadania, pois, isolado, o indivíduo perde a capacidade de convivência e de consciência de seus direitos e deveres. Isolado, tende a ser mais egoísta, mais intolerante" (Oliveira, 2011, p. 83).

Outra questão é pensar o sistema de gestão ambiental das cidades, porque a eliminação das sacolas plásticas, apesar de fundamental para diminuição da poluição nos aterros, nas vias públicas e rios, gerou a sensação de "pagar pela mudança” por parte do consumidor, que se sentiu uma vez mais prejudicado por ter que pagar por sacos para embalar seu lixo, já que a maioria da população utilizava as sacolas plásticas para este fim. Alternativas de descarte do lixo pelo cidadão comum poderiam estar envolvidas nesse processo de mudança desencadeado pela lei de proibição das sacolas, tais como mudanças na construção de prédios e casas, com descarte direto do lixo em recipientes ou contêineres que seriam despejados diretamente no caminhão de lixo, sem a necessidade de embalar o lixo em sacolas plásticas.

Outro aspecto relevante é que o preço das antigas sacolas, que estava embutido no valor da compra dos produtos nos supermercados, não foi abatido da conta do consumidor. Mesmo não recebendo as sacolas plásticas ao finalizar sua compra, o consumidor continua pagando o mesmo preço pelas mercadorias. São desafios que permanecem em uma estrutura em que o cidadão se vê obrigado a se adaptar, assumir novas posturas, mais uma vez desamparado por falta de preocupação e atenção do governo e das empresas. 


\section{Apresentação e análise da pesquisa de opinião nos supermercados}

A análise dos resultados demonstrou que os questionários aplicados (50 questionários no Martplus - Classes A e B; 50 questionários no Supermercado BH - Classes C e D) apresentaram semelhança nas respostas. Os supermercados assim serão representados na análise: $\mathrm{A} / \mathrm{B}$ e $\mathrm{C} / \mathrm{D}$, com suas respectivas porcentagens de respondentes. Observou-se que a maioria dos entrevistados nos supermercados tinha idade entre 26 e 45 anos e eram mulheres. $\mathrm{O}$ que se destacou como diferença entre os dois públicos foram as rendas familiares apresentadas: no supermercado sofisticado a maior parte dos entrevistados sobrevivem com renda superior a $\mathrm{R} \$ 2.000,00$ e no supermercado popular, grande parte sobrevive com renda de até $\mathrm{R} \$ 2.000,00$.

As pesquisas apontam que, apesar de a maioria das pessoas aprovarem a lei e isso ser um sintoma positivo, elas ainda estão inseguras sobre os motivos que levaram o governo a adotar essa iniciativa diante de tantos problemas e quais serão as alternativas para substituição desses costumes, além de não possuírem a garantia de que essa mudança trará efetivamente retorno positivo para todos e para o meio ambiente.

Ao serem questionados se concordariam com a Lei de proibição de sacolas plásticas, observou-se que a maioria é a favor da proibição (A/B: 72\%; C/D: 68\%), o que indica o quão significativa está sendo essa ação para o incentivo na mudança de postura de cada cidadão em relação ao meio ambiente. Quando perguntase "Para que foi publicada essa lei?", inicia-se a análise de envolvimento dos indivíduos com o entendimento das causas ambientais. O que se pode perceber é que tanto as pessoas das classes $\mathrm{A}$ e $\mathrm{B}$ quanto as pertencentes às classes $\mathrm{C}$ e $\mathrm{D}$, em sua maioria, compreendem que essa ação do governo possui interesse de conscientização ambiental para a melhoria da qualidade de vida da população. Também nota-se que algumas pessoas das classes A/B possuem desconfiança em relação às reais intenções dos responsáveis pelo formato da lei, já que as melhores alternativas para substituição ainda não foram evidenciadas, além de ser cobrada a "alternativa" substituta das sacolas convencionais - as biodegradáveis.

A maioria das pessoas (72\% dos pertencentes às classes $\mathrm{A}$ e $\mathrm{B} ; 76 \%$ dos pertencentes às classes $\mathrm{C}$ e $\mathrm{D}$ ) foi informada através de "notícia no jornal, revista e TV", o que evidencia o papel da imprensa na divulgação da lei, em comparação à publicidade instituída pelo poder público. Os números indicam que além de as pessoas terem recebido a informação de proibição de distribuição e uso das sacolas plásticas, ainda tiveram interesse em se informar sobre as características dessa lei, ou seja, se aprofundaram demonstrando um alcance efetivo da imprensa e um aspecto positivo para a mudança de posturas e conscientização. É interessante notar que, apesar de a maior parte dos entrevistados ter respondido que a lei é municipal (A/B: 46\%; C/D: $44 \%$ ), as porcentagens se dividem quase que de forma equilibrada, demonstrando que a responsabilização por iniciativas como essa perpassam todas as instâncias do governo.

A pesquisa de campo comprova que a maioria já estava se conscientizando sobre a importância das discussões ambientais enquanto qualidade de vida (A/B: 78\% positiva; C/D: 70\% positiva). Também é importante destacar a semelhança das respostas dos questionários direcionados às diferentes classes, pois mostram que muitas pessoas já compreendem que o excesso de lixo é um problema e que qualquer medida que contribua na eliminação desses rejeitos será bem aceita.

Nas duas pesquisas ficou comprovado que as pessoas possuem um conhecimento prévio sobre decomposição do plástico, pois grande parte opinou que a degradação desse material é feita através de longos anos, mas esta questão transmite os limites culturais referentes a assuntos ambientais. Pôde-se notar certo grau de diferença no nível de formação crítica ambiental das classes A e B para classes C e D, já que quase 26\% de pessoas das classes $\mathrm{C} \mathrm{e} \mathrm{D}$, responderam levar menos de 20 anos para a degradação das sacolas plásticas. $\mathrm{Ou}$ seja, muitos ainda não possuem noção sobre o impacto do descarte desse tipo de lixo no meio ambiente.

Ambas as pesquisas mostraram que os entrevistados esperam que o poder público assuma a responsabilidade de incentivar e desenvolver a cultura de conscientização ambiental (nas classes A e B 80\% afirmam que a responsabilidade é do governo, contra $70 \%$ entre as classes C e D). Em alguns casos foi percebido que as pessoas passaram essa responsabilidade para o governo por essa ação ter se tornado Lei e não 
apenas um incentivo a uma nova postura. Por um lado, é positivo, pois deve-se esperar que o governo cumpra seus compromissos, mas por outro, mostra-se negativa tal percepção por fazer com que as pessoas esperem que a transformação venha do outro (nesse caso, do governo) e não delas mesmas para mudar a postura frente aos problemas ambientais coletivos.

O questionamento sobre a atuação dos estabelecimentos de compras na campanha de conscientização foi uma das abordagens que mostrou maior discrepância entre os questionários aplicados nos dois perfis de classes. Denunciou que, no supermercado das classes C e D, a maioria das pessoas (68\%) afirmou com convicção não ter ocorrido campanha nos estabelecimentos que frequentam. Já no supermercado de classes $\mathrm{A}$ e B, a maioria das pessoas (52\%) afirmou ter ocorrido campanha nos estabelecimentos que frequentam.

Isso pode indicar que existiram falhas na divulgação, tanto no compromisso do governo em não ter realizado uma campanha educativa eficiente, no qual deveria ter oferecido suporte e informação aos estabelecimentos comerciais para reforçar os objetivos da campanha, quanto dos estabelecimentos das classes mais baixas, que não demonstrarem o interesse em investir em uma campanha educativa para preparar e contribuir com seus consumidores sobre essa mudança cultural, que incidiria diretamente nos seus costumes de consumo.

No supermercado com consumidores das classes A e B foi evidenciado que a maior parte (46\%) está adotando a ecobag, o que significa uma atitude mais conscientizada, já que, para isso, precisam se planejar para levar a sacola retornável ao saírem de casa. Dessa maneira, o indivíduo se mostra envolvido e não espera que o supermercado se responsabilize pelo seu problema, exibindo uma mudança individual com consequências positivas para o coletivo. No supermercado frequentado pelas classes C e D, 26\% usam ecobags e $20 \%$ compram sacolas plásticas biodegradáveis no caixa.

É possível perceber, a partir desses resultados, que existe, na maioria das pessoas que compuseram a amostra, a consciência de que a sacola plástica é prejudicial ao meio ambiente e que qualquer questão que envolva as discussões voltadas aos problemas ambientais e bem-estar social devem ter engajamento e participação da população. Porém, o caso de proibição das sacolas plásticas, apesar de já estar convertido em ação devido à lei vigente, ainda não está devidamente absorvido na mudança de postura e conduta cidadã generalizada.

A mescla de fatores que englobam o assunto, como política, responsabilidade social, cidadania, meio ambiente, provocam uma fusão de influências nos consumidores. Nesse sentido, cabe destacar a grande semelhança dos dados levantados em pesquisa entre as duas classes escolhidas para amostra (as respostas se diferenciam basicamente em apenas três questões do questionário). As pessoas de classes mais elevadas, entrevistadas em supermercado localizado em região elitizada, demonstraram possuir formação crítica mais consolidada em relação ao problema ambiental por serem, possivelmente, dotadas de mais informação. $\mathrm{O}$ mesmo ocorre inversamente com o grupo pertencente às classes $\mathrm{C} e \mathrm{D}$, uma vez que, apesar de se apresentarem concordantes em sua maioria, é notória a presença dos fatores "obrigatoriedade" e "adaptação" para sua mudança de postura e justificativas.

O vereador responsável pela lei sancionada foi quem percebeu todos os indícios e tendências das discussões mundiais em função ao meio ambiente para colocar seu projeto de lei em prática. Em entrevista, o vereador afirmou ter sido simples a aprovação da lei na Câmara, pelo fato de Belo Horizonte não conter grandes fabricantes de sacolas plásticas e nenhum outro fator resistente que pudesse barrá-la.

O vereador contou que a proposta acordada na Câmara em 2008 foi de existir o prazo de três anos de lei facultativa para que fosse realizada a campanha educativa e preparatória pela prefeitura municipal. A intenção de existir tal prazo era de que, pelo fato de a lei incidir diretamente nos costumes dos cidadãos, eles fossem preparados para a mudança dessa postura social em relação aos problemas ambientais e bem-estar social.

A análise nos estabelecimentos de varejo demonstrou o quanto as pessoas estão se preocupando cada vez mais com as questões ambientais mas, apesar de saberem da existência desses problemas, ainda não estão formadas criticamente para compreender os motivos que as levam a essas mudanças e por quê o governo e empresas as pressionam a modificar seus estilos de vida com leis e normas. Como discute Parente (2004), 
“a responsabilidade social no varejo ajuda também a estender as práticas socialmente responsáveis à cadeia produtiva”.

Em 2012, o Ministério Público conseguiu, na Justiça, eliminar a cobrança, alegando formação de cartel por parte dos supermercados e que não havia retorno ambiental na adoção das sacolas biodegradáveis (Pedrosa, 2015). A proibição da venda ainda permanece, porém alguns estabelecimentos recuaram e estão distribuindo as embalagens de graça, sob pena de distanciamento de alguns consumidores, o que vem aumentando o seu uso.

Portanto, percebe-se que a mudança das sacolas plásticas indica uma questão mais estrutural, de reformulação de toda a cadeia, um sistema de produção e consumo, estando o consumidor no meio deste processo, muitas vezes perdido, até querendo se inserir, mas sem as condições necessárias para uma efetiva participação.

\section{CONSIDERAÇÕES FINAIS}

Como principal resultado desta análise sobre a aprovação e implementação da lei municipal 9.529/08, são destacadas as falhas de concepção e implementação que não permitiram o pleno funcionamento do plano de ação inerente à lei, identificadas e problematizadas na pesquisa. Dessa forma, foi possível apontar vulnerabilidades da campanha de divulgação e pode ser observado que nenhuma das partes envolvidas se responsabilizou por tais falhas. $\mathrm{Na}$ sensibilização para o consumo sustentável, os varejistas poderiam ter assumido um papel relevante, já que o varejo é o um setor que possui intimidade com o consumidor final. De acordo com Belinky (2006), o varejo é o setor que mais possui contato direto com o consumidor e possui uma abertura ideal para incentivar a mudança de postura, fazendo uso da comunicação para incentivar a cidadania e a educação do consumidor. O setor privado, na verdade, ficou como um intermediário em todo o processo. O setor público, por sua vez, promoveu a mudança via legislação, mas também não se moveu de maneira suficiente para que a sensibilização e a fiscalização fossem efetivas.

A análise nos estabelecimentos de varejo demonstrou o quanto os indivíduos, através desse tipo de ação - ser proibida a distribuição das sacolas por lei -, estão se preocupando cada vez mais com as questões ambientais, mas apesar de saberem da existência desses problemas, elas ainda não estão formadas criticamente para compreender os motivos que as levam a essas mudanças. Sintomas assim são visivelmente percebidos no varejo por englobar toda a cadeia de produção, destinação e consumo de produtos.

O que poderia ter sido realizado pela Prefeitura, em parceria com empresas e organizações ligadas ao varejo, no período facultativo da lei, era a conscientização e a preparação dos indivíduos e estabelecimentos (incentivos de campanhas, colaboração com stands de informação, etc.) para essa transformação do consumidor moderno, o qual deverá se reformular para se adaptar ao novo formato de relacionamento com todo o ambiente que o cerca. Portanto, uma ação conjunta e coordenada entre setor público, privado e os cidadãos.

A forma como a lei de proibição das sacolas plásticas se manifestou nos consumidores acabou sendo positiva, por ter tornado a ação de mudança uma lei, ou seja, efetivamente, a questão se tornou uma política pública, e negativa pelo fato de não ter oferecido o suporte necessário para a transformação das consciências das pessoas em relação a esse problema. Consequentemente, induziria o indivíduo a um entendimento de que essa lei será a porta para novas discussões ambientais e futuras conquistas para melhorias no bem-estar social coletivo.

Parente (2004) indica que o desenvolvimento sustentável do varejo auxilia a estender as práticas da cadeia de produção, envolvendo fornecedores, distribuidores e, sobretudo, consumidores. Tais perspectivas apontam que a lei das sacolas é apenas o primeiro passo da mudança. Apesar de impactar toda a população de uma cidade, é uma ação pequena quando confrontada com o que precisa ser feito, pois, como reforça Shove (2012), a simples instituição de regras e proibições não diminui a utilização de recursos. Esse acanhado, porém 
importante passo tem como objetivo gerar uma responsabilização sobre a sustentabilidade, promovendo o desenvolvimento de novas práticas sustentáveis em toda a cadeia de produção e consumo. Desta forma, é possível notar que cada vez mais os cidadãos estão percebendo o quanto é preciso repensar posturas, uma nova forma de agir não só de consumidores denominados “verdes”. Vislumbra-se, portanto, crescente mudança de postura dos cidadãos para a sustentabilidade (Lipovetsky, 2007).

Os mais recentes capítulos dessa história apontam que a questão é polêmica. A lei municipal, pioneira no Brasil, foi sobreposta quando entrou em vigor, em 2015, a regulamentação estadual para as sacolas plásticas. A regra municipal previa apenas o uso do plástico biodegradável (compostável), mas a legislação do Estado defende que esse tipo de sacola só pode ser exigido em cidades que possuem coleta seletiva e usina de compostagem. Portanto, municípios mineiros que não atendem a esses requisitos, como é o caso da capital, têm que permitir plásticos oxibiodegradável e reciclável.

De acordo com a Associação Mineira de Supermercados, o consumo de sacolas caiu de 450 mil por dia para cerca de 100 mil a partir da vigência da lei. Nos primeiros meses após a proibição, o consumo diário baixou para 13 mil unidades, período em que se chegou a cobrar pela embalagem. Como em 2012 o Ministério Público eliminou a cobrança, alegando que não havia retorno ambiental na adoção das sacolas biodegradáveis e formação de cartel por parte dos supermercados (Pedrosa, 2015), alguns estabelecimentos recuaram e estão distribuindo as embalagens gratuitamente, sob pena de distanciamento de alguns consumidores, o que vem aumentando o seu uso. Nesse sentido, a lei perde força e a sustentabilidade parece ceder lugar à exploração do sistema econômico vigente.

As limitações deste estudo se baseiam na pesquisa qualitativa com definição de alguns atores para composição do campo estudado. Estudos futuros que relacionem novas fontes de pesquisa, como, por exemplo, um estudo quantitativo aprofundado e com ampla base de dados, que correlacionem, por exemplo, as opiniões dos cidadãos de diferentes cidades, poderão aprofundar as reflexões aqui propostas de maneira a fomentar o desenvolvimento sustentável.

\section{REFERÊNCIAS}

Abramovay, R. (2012). Muito além da economia verde. São Paulo: Ed. Abril.

Antonetti, P.; Maklan, S. (2016). Hippies, Greenies, and Tree Huggers: How the Warmth Stereotype Hinders the Adoption of Responsible Brands. Psychology \& Marketing, 33 (10), 796-813.

Bardin, L.(2011). Análise de conteúdo. São Paulo: Edições 70.

Bauman, Z. (1999). Globalização: as consequências humanas. Rio de Janeiro: Jorge Zahar.

Belinky, Aron. (2007). De "cidadão que consome" a "consumidor cidadão". In: Antas Jr., Ricardo Mendes (Org.). Desafios do consumo. São Paulo: Vozes.

Boyer, R. H. W. (2015) Grassroots innovation for urban sustainability: comparing the diffusion pathways of the three ecovillage projects. Environmental and Planning, v. 45, p. 320-337.

Brasil. Senado Federal. (2014).Resíduos sólidos: os lixões persistem. Revista em Discussão!, 5(22).

Brought, A. R.; Wilkie, J. E. B.; Ma, J.; Isaac, M. S.; Gal, D. (2016).Is Eco-Friendly Unmanly? The Green-Feminine Stereotype and Its Effect on Sustainable Consumption. Journal of Consumer Research, 43(4), 567-582.

Canclini, Néstor García. (2006). Consumidores e cidadãos: conflitos multiculturais da globalização. Rio de Janeiro: Editora UFRJ.

Chappells, H.; Medd, W.; Shove, E. (2013). Disruption and change: drought and the inconspicuous dynamics of garden lives. Social \& Cultural Geography, 12(7): 701- 715.

Chen, T. B.; Chain, L. T. (2010). Attitude towards the environment and green products: consumer's perspective. Management Science and Engineering. 4(2). 
Cherrier, H. (2007). Ethical consumption practices: Co-production of self-expression and social recognition. Journal of Consumer Behaviour. 6(5): 321-335.

Costa, D. V.; Teodósio, A. S. S. (2011) Desenvolvimento sustentável, consumo e cidadania: um estudo sobre a (des)articulação da comunicação de organizações da sociedade civil, do estado e das empresas. Rev. Adm. Mackenzie (online), São Paulo, 12(3): 114-145.

Costa, H.; Tutida, D.K.A.; Machado, J.M.; Nunes, (2014). R. S. A sustentabilidade endossando o consumismo contemporâneo: uma reflexão crítica. Revista Percurso. 14(01).

Dias, R. (2007). Marketing Ambiental: ética, responsabilidade social e competitividade nos negócios. São Paulo: Atlas.

Engelman, R. (2013). Além do Blablablá da Sustentabilidade. In: Assadourian, E; Prugh, T. Estado do mundo 2013: A Sustentabilidade Ainda é Possível? Salvador: Worldwatch Institute.

Fisher, T. (2014) Public Value and the Integrative Mind: How Multiple Sectores Can Collaborate in City Building. Public Administration Review, v. 74, i. 4, p. 457-464.

Fontenelle, I. (2009). Coolhunters: pesquisas de Mercado de 'tendências culturais' e transformações na comunicação mercadológica contemporânea. In: Filho, Clóvis Barros et. al. CAEPM (org.). Bravo mundo novo: novas configurações da comunicação e do consumo. São Paulo: Alameda.

Giacomini, Gino. (2004). Ecopropaganda. São Paulo: Editora Senac.

Gife [Grupo de Institutos Fundações e Empresas] (2011). Recuperado em 11 abril 2001, de www.gife.org.br.

Gonçalves-Dias, S. L. F., Teodósio, A. S. S. (2006). Consumo Sustentável: é possível reformular as opções de consumo? In: Anais do 2o. Congresso Acadêmico sobre Desenvolvimento e Meio Ambiente - CADMA, Rio de Janeiro, $1: 1-12$.

Hamman, P.; Anquetin, V.; Monicolle, C. (2017) Contemporary Meanings of the 'Sustainable City': A Comparative Review of the French - and English - Language Literature. Sustainable Development, 25, p. 336-355.

IBGE (2010). Pesquisa nacional de saneamento básico 2008 - Coordenação de População e Indicadores Sociais. Rio de Janeiro, 2010. Recuperado em 10 março 2018, de https://www.ibge.gov.br/estatisticas-novoportal/ multidominio/meio-ambiente/9073-pesquisa-nacional-de-saneamento-basico.html? $=\& \mathrm{t}=$ sobre.

Jacobi, P. (2006). Cidade e Meio Ambiente: percepções e práticas em São Paulo. SP: Annablume.

Knight, A. (2011). Sustainable consumption: the retailing paradox. 2004. Recuperado em 15 abril 2011, de http://www.sdcommission.org.uk/publications/downloads/040501\%20 Sustainable\%20Consumption, \%20the\%20Retailing\%20Paradox.pdf.

Lei $\mathrm{n}^{\circ} 9.529$ de 27 de fevereiro de 2008. (2008). Regulamenta a proibição de sacolas plásticas convencionais. Lei Orgânica do Município.

Lipovetsky, G. (2007). A Felicidade Paradoxal. Ensaio sobre a sociedade de

Lipovetsky, G.; Roux, E. (2005). O luxo eterno: da idade do sagrado ao tempo das marcas. São Paulo: Companhia das Letras.

Macedo, L. C. (2007) Responsabilidade social empresarial e sustentabilidade na cadeia de valor do varejo. Trabalho de Conclusão de Curso (Especialização em Gestão de Sustentabilidade) - Escola de Administração de Empresas de São Paulo da FGV São Paulo.

Matos, E B. (2013). Comportamento e meio ambiente: Um estudo comportamental da intenção de não uso das sacolinhas de plástico. REGE - Rev. Eletrônica de Gestão, São Paulo, v. 20(2):217-232.

Naves, F. L. (2004). Saberes, poderes e os dilemas das relações socioambientais. Organizações Rurais e Agroindustriais. Lavras, 6(2): 121-133.

Okada, E. M.; Mais, E. L. (2010). Framing the "Green" alternative for environmentally conscious consumers. Sustainability Accounting, Management and Policy Journal, 1(2):222-234.

Oliveira, M. J. C. (2011). De públicos para cidadãos: uma reflexão sobre relacionamentos estratégicos. In:Relações Públicas Estratégicas: técnicas,conceitos e instrumentos. São Paulo: Summus.

Painter-Morland, M.; Demuijnck, G.; Ornati, S. (2017) Sustainable Development and Well-Being: A Philosophical Challenge. Journal of Business Ethics, 146, p. 295-311. 
Parente, J. (2004). Responsabilidade social no varejo: conceitos, estratégias e casos no Brasil. São Paulo: Saraiva.

Pedrosa, A. P. (2015). Lei estadual da sacola plástica entra em conflito com a de BH. Jornal O Tempo. Recuperado em 12 de outubro de 2015, de http://www.otempo.com.br/capa/economia/ lei-estadual-da-sacolapl\%C3\%A1stica-entra-em-conflito-com-a-de-bh-1.969731.

Portilho, F. (2005). Sustentabilidade Ambiental, Consumo e Cidadania. São Paulo: Cortez.

Sachs, I. (1986). Ecodesenvolvimento: crescer sem destruir. São Paulo, Vértice.

Santos, L. L. (2005). Comunicação e consumo sustentável: das entrelinhas do capitalismo leve ao enquadramento da sustentabilidade na mídia. Rev. Fronteiras - Estudos Midiáticos. VII. P. 223-233.

Semprebon, E.; Mantovani, D.; Demczuk, R.; Luz, V. V.; Galvão, F. H. S. (2017). Green Consumption: A Network Analysis of Theoretical Relationships in Marketing. EnANPAD (2017), São Paulo - SP. Anais do Enanpad 2017.

Shove, E. (2012). The shadowy side of innovation: unmaking and sustainability. Technology Analysis \& Strategic Management, 24 (4):363-375.

Shove, E. (2012a). Putting practice into policy: reconfiguring questions of consumption and climate change. Journal of the Academy of Social Sciences.

Silva, M. E. S.; Slongo, L. A. (2014). A estratégia do marketing de relacionamento para o consumo sustentável: um estudo no varejo. AOS - Amazônia, Organizações e Sustentabilidade. 3(2): 153-173.

Silva, M. E.; Cândido, G. A. (2014). The business contribution for sustainable consumption: a proposal of theoretical categories and analytical parameters, Revista Eletrônica de Ciências Administrativas - RECADM, 13 (1).

Slater, Don. (2002). Cultura de Consumo e Modernidade. São Paulo: Nobel.

SLU (2018). Seção de Estatística da SLU. Recuperado em 25 março 2018, de: https://prefeitura.pbh.gov.br/slu/ informacoes/estatisticas.

Viegas, D. (2010). Consumo sustentável e cidadania: reflexões sobre a atuação de empresas, sociedade civil e estado na comunicação para a mobilização socioambiental na realidade de Belo Horizonte. Dissertação de Mestrado. Centro Universitário UNA.

\section{BY-NC-ND}

